\title{
Erratum to "An Economic Instrument to Improve Society" [Theoretical Economics Letters, 9, 1804-1816]
}

\author{
Jan Stenis \\ Kristianstad, Sweden \\ Email: jan.stenis@icloud.com
}

How to cite this paper: Stenis, J. (2021). Erratum to "An Economic Instrument to Improve Society" [Theoretical Economics Letters, 9, 1804-1816]. Theoretical Economics Letters, 11, 447-461. https://doi.org/10.4236/tel.2021.113029

Received: April 16, 2021

Accepted: May 31, 2021

Published: June 3, 2021

Copyright $\odot 2021$ by author(s) and Scientific Research Publishing Inc. This work is licensed under the Creative Commons Attribution International License (CC BY 4.0).

http://creativecommons.org/licenses/by/4.0/

\section{(c) (i) Open Access}

The original online version of this article (Stenis, J. and Hogland, W. (2019) An Economic Instrument to Improve Communities. Theoretical Economics Letters, 9, 1804-1816. doi: https://doi.org/10.4236/tel.2019.96115) unfortunately contains some mistakes. The author wishes to delete the co-author and correct the errors in the main text.

\begin{abstract}
Objectives: A general strive exists for achieving the wanted results with as limited resources as possible. There is a need for ever more cost-effective organisations, making this paper required to improve the policy efficiency and raise the technological standard in various communities. The Naturally Optimised Revenue Demand in Communities (NORDIC) model is introduced to improve the flow of physical and intangible utilities through entities of different kinds, such as producing companies and nations. The launched economic instrument also improves the ecological footprint of the organisations in question. Methods: The basis for the work is the existing Efficient Use of Resources for Optimal Production Economy (EUROPE) model, which is developed to become more powerful. Constructed shadow costs are added to the bookkeeping systems of organisations to give economic incentives to improve the economy, technology and environment. The design of the scientific work emphasises a logical-historical disposition. Results: The NORDIC model gives managers a management tool. The model is applicable to the public sector and commercial activities. The method provides a key indicator to assess and improve actors' performance. A manual for the practical use of the NORDIC model is presented. The case study shows how to induce an economic incentive to reduce the costs and increase the efficiency for the health care, education and social services in the nation of Sweden. Conclusions: The model shows utility for various entities, such as public sectors, within nations. Citi-
\end{abstract}


zens get a better life, and improved health, due to a better economy when the results in this paper are implemented. In the future, studies could be conducted to determine how the NORDIC model can be applied to larger units. There is potential to apply the model to the international context.

\section{Keywords}

Nordic Model, Efficiency, Utilities, Flows

\section{Introduction}

\subsection{Scientific Background}

The background for this work is the common strive for achieving the wanted results with as limited resources as possible. This general motivation points at the importance of the subject. The need for ever more cost-effective organisations justifies taking up the study. This paper is required to improve communities. The Naturally Optimised Revenue Demand in Communities (NORDIC) model is introduced. The objective is to improve the flow of physical and intangible utilities through different entities, such as producing companies and nations. The Efficient Use of Resources for Optimal Production Economy (EUROPE) model [1] [2] [3] [4] [5] is developed to become even more powerful. Furthermore, the practical use of the EUROPE model [6] is improved. Shadow costs, or prices [7] constitute the basis.

\subsection{Methodology}

The design of the scientific work emphasises a logical-historical disposition. It follows the research process that contains, for example, the background, presentation of the problem and theory used, description of the data collection and processing, the analysis of the results and the conclusions and recommendations. Explanative investigations are featured to investigate the causal relationship between the variables in the new model. The investigation is also explorative since the study seeks new knowledge to present in the written form.

The main hypothesis in this paper is that the flow of physical and intangible utilities through entities of different kinds can be improved by applying the NORDIC model. The main goal is to facilitate the daily use of the NORDIC model by managers and practical operators. The nation of Sweden was chosen as the object of a case study for the following reasons: first, there are good, statistical data available on nations; and second, Sweden offers an extensive public sector for the case study. More broadly, I hope that this study will contribute to improving the economic, environmental and technological standards for organisations, which also improve the living conditions for related communities. The research gap that this study aims to fill is the need to develop new economic instruments to manage communities. The case study concerns the application of 
the NORDIC model to public sector activities. The research questions that I address are: 1) How can I use my NORDIC model to improve the economic efficiency of communities, such as the health care, education and social services? 2) How can a versatile economic tool be developed for this purpose? 3) For whom is this tool important? and 4) Who are the other potential final users (apart from governments)? Based on the results from the case study, I explore how the NORDIC model can be applied in practice to promote economic, environmental and technological improvements, and who would benefit from the endeavour. The answers to these questions will guide the relevant civil servants and financiers when performing project appraisals of the profitability and sustainability while considering the ethical aspects.

The research contributions of this paper are that it provides a better understanding of how community management can be facilitated by the application of economic instruments, and the development of a manual to help the managers and operators who employ the NORDIC model. This paper introduces a method for improving the flow of physical and intangible utilities through entities, such as producing companies and nations. Managers are provided with a single, key factor to simultaneously monitor, manage and evaluate their projects.

The NORDIC model is a tool to monitor, manage and evaluate how the economic, technological and environmental performance of a firm or a community changes over time. The method involves adding so-called shadow costs to economic systems. A shadow cost is commonly referred to as a monetary value assigned to currently unknowable or difficult-to-calculate costs [7]. These shadow costs are inserted into the budgets and accounting systems of the entity using the NORDIC tool. The changes that occur over time in the shadow costs provide a versatile tool that enables organisations to reduce the inefficiencies of the flows that these shadow costs are allocated to, one by one, in order of declining importance, or lowering the costs of the flows in question. In both cases, it is considered that the versatile NORDIC model can be applied to produce robust results, given the inherent logic of the mathematical theories underlying the model, and its good application in the presented case study.

Mainly, the problem has been analysed from a public perspective. The research approach aims at creating modification of models and theories. Rather few parameters are used to move the research frontier ahead. The study's intention is also to present certain applications of economic model theory about the welfare sector. The tool is case study technique.

The research problem is centred around accomplishing a change. The choice of method is centred on stakeholders through case studies. The results are increased knowledge.

An analytical approach is applied to develop theories and models. The hypotheses are analysed and verified. Consequences are explained and the causal relationships are investigated and described. Information was obtained through Internet sources and personal E-mail contacts. The obtained results are generalised 
to enable a continued accumulation of knowledge. Empirical facts are observed to induce theories and deduce predictions to obtain and verify new facts.

When modifying the present economic models, an analytical, economic-logic approach is mainly applied. A descriptive systems theory is used for the model's context. A non-personal approach is chosen that is more positivistic than, for example, humanistic.

An attempt is made to describe and establish as a part of the results and to predict and guide as a part of the discussion. The prediction is tested to induce discussed theories. Concrete actions to take are suggested to improve the problem situation in economic, environmental, and technological terms. Recommendations for the suggested and relevant actors are given, based on the statements about the findings, provided in the present study.

The sources of information for the study have included relevant literature and articles and database search, the Internet and personal E-mail contacts. This data is processed. Thus, trustworthy, secondary data is used, because primary data is new and unprocessed.

The quantitative research methodology is prevailing since the scientist is a detached observer, more than part of the study himself. The passing from theory to empiric encompasses an operationalisation by employment of the defined concepts for certain exemplified units. The processing of neutral data takes place in the detached case study.

Traditional economic modelling constitutes the validity of the methods developed in this study. The use of relevant literature and the relevant case study grant the reliability.

The instrument that is developed in this work is based on financial incentives. It is hence an economic instrument (EI) which strengthens the dialogue between different actors.

The concepts presented here contribute to reducing the misuse of resources in society. The external environment will improve by time to enhance the citizens' quality of life.

\section{Literature Review}

The purpose for the literature review was to explore the previous findings, which may contribute to the model-development of this study. The literature review resulted in the author's discovery of some scientific theories and models, showing a certain resemblance with the previously introduced EUROPE model and the new NORDIC model, which is based on the EUROPE model. For example, the following approaches can be mentioned.

The review of the earlier findings, mainly within the fields of economy, models and optimisation theory, resulted in information about, for example, Sekerka and Stimel [8] having studied how and why firms move to engage in sustainable enterprise. Ooi [9] studied the transition and evolutionary models of urban en- 
vironmental development. Blake [10] used a regression model to measure political attitudes and environmental knowledge, which include effects of individual action related to environmental causes. Huang, Liu, $\mathrm{Ma}$ and $\mathrm{Su}$ [11] have presented a new data envelopment analysis-based model for quantifying vulnerability to natural hazards in China. Hills [12] found that a conventional commandand-control model focusing on pollution control drives environmental policy making in Hong Kong. Phyllis et al. [13] applied a model that uses fuzzy logic, called SAFE, to measure the sustainability of a country, based on a multitude of basic indicators. Gavazov et al. [14] coupled experimental and modelling approaches to assess the impact of climate change with a spatially explicit model. Jepson [15] proposed the incremental integration of the expansionist and ecological views, using a decision model that incorporates project and context information to identify appropriate method and role.

More recently, Dror [16] has stated that the interest in the study and improvement of policymaking has been on the increase since around 2002, but no breakthroughs have occurred. A few, useful concepts have been developed, but no major advances in policymaking theory have taken place. No shift for the better in overall policymaking has occurred. In 2011, Vedung [17] suggested that one should concentrate on the generic tools of government action, public programs and says that the alternative tools of public action are the real "missing link" in the theory and practice of public management. These findings point at the approach presented in this paper being in line with the current movements of public management theory. Thus, the NORDIC model contributes to solving the problem of how to improve the overall policy efficiency for government action and public programs.

Regarding the use of shadow costs as a model component, Matsumura and Tomaru [18] introduced shadow costs of public funding as "the excess burden of taxation" and found that in a mixed duopoly, the level of product differentiation is too low for social welfare, in sharp contrast to the private oligopoly, where the level of product differentiation is too high. They showed that when the shadow cost is high, privatizing the public enterprise improves the welfare. However, according to Pentland [19] market thinking can easily go wrong. This work exhibits low amounts of employed shadow costs as the tool for improving enterprise efficiency. Thus, public enterprises are less likely to be privatized due to the application of the findings about economic modelling in the present paper.

This literature review shows that few scholars have developed models to obtain economic instruments that use shadow costs, or shadow prices, to optimize the performance of activities related to welfare-issues. Most studies only describe the technical aspects. Few studies have examined how to monitor, measure and evaluate, in monetary terms, the performance of activities, using a single, key factor. This work hence presents a promising approach to analysis of enterprises to improve the welfare of communities and nations. 


\section{Research Methods}

The EUROPE model [1]-[6] formed the basis for the present work. The EUROPE model was adapted to community issues with emphasis on health care, education and social services to design the NORDIC model.

\subsection{The Subjects}

The basis for the work is the existing EUROPE model. This concept is further developed into an even more versatile expression denoted the NORDIC model. The components of the EUROPE model are studied and reduced to improve the model's generality, and tested on the Swedish, public sector in a case study that employs real-world facts and figures.

\subsection{The Study Procedures}

\subsubsection{Experimental Interventions}

Personal computers were used as the main tool to acquire and process relevant data. Thus, no direct intervention with humans and/or animals took place during the conducted work. The author hence was highly detached when performing the present study, without being impersonal due to the many humans affected by the results of this study, if implemented.

\subsubsection{Sampling Procedures, Sample Size and Ethical Considerations}

Recent and reliable data were obtained from reliable and public Internet sources. No agreements or payments were made. The sample size was the care, schools and welfare, Swedish: vård, skola, omsorg, in the nation of Sweden. No living individuals or animals were directly involved. The study required no particular physical safety precautions or special arrangements to prevent harming the objects of study.

\subsubsection{Measurement Approaches}

Observations of the important and relevant study-groups via online sources were made. Only reliable sources on the Internet were consulted. Usage of impersonal socio-economic data granted the cultural validity when processing the obtained information.

\subsubsection{The Research Design}

In practice, the research methods of this paper are designed as follows. First in the manuscript, a descriptive Introduction gives the background for this work and points at the importance of the subject. The need for taking up the study is clarified and why this paper is required. The new acronym NORDIC is explained and how it is related to the acronym EUROPE, whose scientific basis is given in the references by the author. The literature review that follows displays the outcome of the authors' search for relevant, scientific references mainly within economy, models and optimisation theory. In this Research methods section, the mathematical basis for the new NORDIC model is given in two equations that are 
easy to apply to the study objects in question. The Analysis that follows gives the general principle for how the NORDIC model improves the situation in organisations and tells managers how to act when the shadow cost $S C$ changes, and why they should do it. Next, a manual is given to show how the NORDIC model should be applied step by step. Thereafter, the usefulness of the NORDIC model is tested with real-world data in a case study on the health care, education and social services in the nation of Sweden. Then, the results are discussed and at the end of the Conclusion's section, the conclusions are listed, the theory-limitation is given, and future research suggested. Finally, the benefits of using the NORDIC model and recommendations for its application are provided.

\subsection{Theory Foundation}

The NORDIC model is expressed by Equations (1) and (2).

The shadow cost: $S C=(X / Y) * Z * W$

The entity to be optimized: $X=V-C$

where $S C$ represents the positive shadow cost; $X=(V-C)$ represents the net worth of the entity to be optimised, or at least improved, if optimisation is not feasible; $V$ represents the value of $X ; C$ represents the cost of $X ; Y$ represents the sum of the entities to be optimised, or improved; $Z$ represents the value of the activities connected to $X$, and; $W$ represents the weight factor (without unit, it is a decimal value) for the impact on society by $X$, per period for an administrative unit that is studied. Unit: currency, kilogram, litre or Joule.

\subsection{Application of the NORDIC Model to Communities}

The constructed, but useful, shadow cost $S C$ is additionally inserted into the profit and loss account of the studied organisation in question to accomplish monitoring, management and evaluation of the development of $X$. The addition of $S C$ gives strong economic incentives to improve the current situation, if $S C$ is considered as a real phenomenon to be applied.

\subsection{Logical Analysis of the Introduced Theory}

If $S C$ increases, this means that the organisation in question has improved, as regards optimising, or improving, $X$. When $S C$ decreases over time, this calls for corrective actions to be taken by management to avoid inefficiencies with a negative impact on the economy. In practice, $S C$ is continuously monitored to detect signs of a declining resource economy.

\subsection{Manual for the Practical Application of the NORDIC Model}

Constructed shadow costs are added to the values of economic significance, to improve the efficiency of the resource utilization in the targeted organisations. This procedure increases the shadow costs, if $X$ is useful and yields revenues. The cost development is studied over time to make the phenomenon in question 
more cost-effective. The manual that guides managers when applying the NORDIC model in practice, involves the following key steps.

1) Determine which losses to pinpoint, step by step, by estimating $X$.

2) Estimate $Y, V$ and $C$ using the studied organisation's book keepings.

3) Determine $Z$ and/or the total breakdown cost from the actor's ledgers.

4) Determine the weight factor $W$ for the organisation's impact on society.

5) Calculate $S C$ and insert it into the accounting system of the current entity.

6) Determine $S C$ for any additional item $X$ of commercial or public interest.

7) Re-calculate $S C$ to study it carefully to monitor, manage and evaluate $X$.

8) Take actions to increase the organisation's efficiency, if $S C$ decreases.

\subsection{The Swedish Health Care, Education and Social Service in 2018}

By Equations (1) and (2), $X$ represents the Swedish health care, education and social services. $X$ given by the Swedish municipalities' purchases of services was 11.5 billion US dollars (SEK115 billion) [20]. The corresponding figures for the Swedish county councils was 5.8 billion US dollars (SEK58 billion) [20].

$Y$ represents the Swedish state's expenses for education (SEK76 billion) plus health care and social services (SEK78 billion) and was 15.4 billion US dollars [21].

$Z$ represents Sweden's GDP from public administration and was 22.6 billion US dollars (SEK226 billion) [22].

$W$ represents the relative life expectancy in Sweden and was 98 percent of the maximum rank globally for both sexes [23].

A conversion rate of US dollars $1=$ approx. SEK10 (March 2021) is used throughout.

Equation (3) produces the shadow cost for the health care, education and social services:

$$
\begin{aligned}
S C_{\text {Sweden }}= & \frac{11.5 \text { billion US dollars }+5.8 \text { billion US dollars }}{15.4 \text { billion US dollars }} \\
& * 22.6 \text { billion US dollars } * 0.98 \\
& =25 \text { billion US dollars }
\end{aligned}
$$

$S C_{\text {Sweden }}$ is added to the public finances of Sweden to induce an economic incentive to reduce the costs, and increase the efficiency, for the Swedish health care, education and social services. The general principle for application of $S C$ to nations is shown in Table 1 .

\subsection{Sensitivity Analysis of the Introduced Theory}

Figure 1 shows how the resulting shadow cost $S C$ varies with the entity $X$ to optimise, in this case. The relationship between $S C$ and $X$ is linear, pointing at the introduced NORDIC model producing reliable output regardless of the input's values. This is a strength of the launched methodology and truly enhances the model's reliability and trustworthiness. 


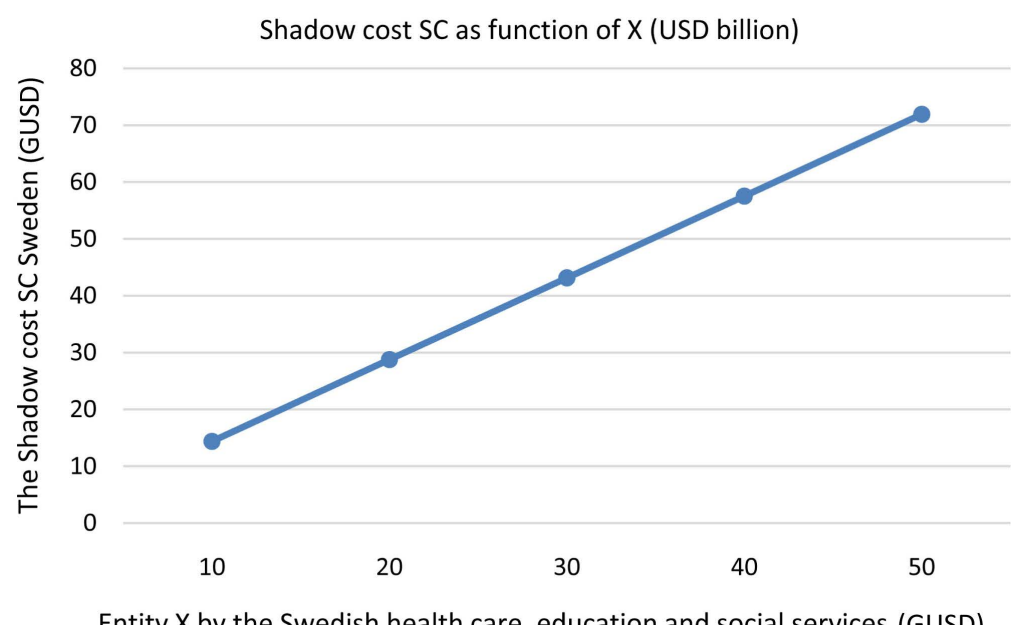

Figure 1. $S C$, as a function of the entity $X$, in the case study.

Table 1. The public finances of Sweden.

$$
\begin{gathered}
\text { Revenues } \\
S C_{\text {Sweden }}(25 \text { billion US dollars }) \\
\text { Expenditures } \\
\text { PSBR ( }-25 \text { billion US dollars })
\end{gathered}
$$

\section{Results and Discussion}

The benefit of the NORDIC model is that the shadow cost provides management with an instant view of the performance of their business. The $S C$ conveys important aspects of how the community performs. Thus, a better possibility for CEOs to manage well is the major value of knowledge added by the paper. The previously developed EUROPE model provided an economic instrument, which was more developed into the NORDIC model.

The case study exhibits the practical usefulness for the NORDIC model, also on higher, administrative levels. A reasonable shadow cost of 25 billion US dollars is obtained, compared to the Swedish GDP of 555 billion US dollars in 2018 [24]. Thus, the NORDIC model can be used where a "black box" system is present. Ultimately, the gain from using the model is a better life for the citizens, due to the strengthened economy. The model shows utility for entities, such as nations. $S C$ constitutes a versatile tool. The reliability is good because the outcome of the case study gives a realistic result.

The main strength of the model is its generality. The disadvantages are the less good precision when employing the shadow costs, and the difficulties to get access to input data to apply the theory in practice. Further research can develop mathematical algorithms adapted to the public sectors and add some relevant factors to the current model-design.

Examination of $S C$ over time shows the changes in the organisational efficiency. $S C$ is a key indicator. If $S C$ decreases compared with the previous years, 
this calls for actions, such as the implementation of measures to improve the performance. Thus, the $S C$ constitutes an economic warning signal that managers seriously should consider as their decision basis.

A substantially decreased $S C$, compared with that of the previous year, indicates that major changes are required, whereas a small change may indicate that only small adjustments are required. Management can design its own rules regarding when and how to act, depending on the extent of the changes in $S C$. Different degrees of changes in $S C$ give rise to different actions, depending on the changes' size and relative speed of varying.

The shadow cost $S C$ increases proportionally with $X$. It is unproblematic to apply the launched model to different organisations to provide an improving instrument. The application of the new, economic instrument can be performed, regardless of the $X$ decreasing or increasing, compared to its original value, due to the linear relationship (Figure 1).

$S C$ in the NORDIC model does not directly show the value of the communities' equipment. Nor does the NORDIC model consider the size of the organisation's assets. $S C$ provides an indicator that indicates how efficiently the community uses its resources over time to produce utilities. In the present case study, the costs of the Swedish health care, education and social services are optimized, or at least reduced, over time by using the NORDIC model, and the constructed $S C$, to indicate the efficiency improvements. Here, $S C$, depending on $X$, denotes an entity of positive value for the actor in question. If not so, the negative value of $X$ is to be considered, and inserted constituting a PSBR-raising expenditure.

It cannot be determined what specific actions that should be taken by studying the changes in the $S C$. A decreased $S C$ indicates that actions should be carried out, but not exactly which ones. Determining the appropriate actions is a task for the civil servants in consultation with their CEO.

If the $S C$ decreases from one year to the next, the management understands that it must act. The NORDIC model alerts management that it must act but leaves the determination of the improvements to the employees and $\mathrm{CEO}$ of the current organisation. If the $S C$ increases from one year to the next, the NORDIC model tells management that the business has improved, in general terms.

The NORDIC model does not enable to determine in detail which solutions should be implemented. It indicates that when the $S C$ decreases, there is an issue with the system that requires action. The model does not indicate precisely which solution the CEO will choose. It provides managers with an overview.

This is how economic instruments work in general. The development of the NORDIC model includes a stepwise manual that covers its practical application. This manual that is presented in Section 3.6, provides the very step-by-step instructions for application of the launched model. In this paper, the NORDIC model is based on currency as the dominant unit for the model calculations, rather than physical entities.

In the case study, the fraction $X$ is a certain public sector. The step-by-step 
manual shows how CEOs should use the NORDIC model in practice. It is not possible to provide detailed suggestions about what actions to take, as part of the model, but CEOs should learn the principles for applying the NORDIC model in practice. When the NORDIC model indicates that measures are required to increase the efficiency of the organisation, the CEO will approach the organisation's managers to determine the solutions required.

The NORDIC model gives not the very solutions. It provides an economic instrument to monitor, manage and evaluate the performance. The employees design the innovative solutions required when the CEO determines the need to find creative solutions. In the short run, the NORDIC model will not result in zero loss goals being met. By applying the model and the manual instructions, over time the losses can decrease, focusing first on what are of greatest importance to achieve in terms of profitability and environmental impact.

This method will have a positive impact on the private behaviour in minimizing losses. The $X$ in Equations (1) and (2) increases over time when the organisation becomes more resource effective. Thus, when management tries to increase its $S C$, its actions will include encouragement and incentives for reducing losses, and improve the behaviour exhibited by the citizens being affected by the practical implementation of the NORDIC model.

The NORDIC model can assist in achieving an objective. The NORDIC model can guide in making a desired fraction more efficient, by lowering operational costs. Also, the model provides management with a better understanding of the cost-situation for the $X$ factor.

The case study presented here shows the viability of the NORDIC model, when applied to Sweden's public finances, to improve the performance of the Swedish health care, education and social services. The case study results in the calculation of a rather reasonable shadow cost $S C$ of 25 billion US dollars, which managers can utilize to guide their own decisions. $S C$ provides a comprehensive key indicator, which summarizes the performance of most organisations also in other sectors than the public, as in the present case study.

$S C$ is a constructed entity that is added to the revenue of the organisations that use it. The addition of $S C$ to the revenue results in an incentive for management to start increasing the fraction $X$, or to decrease the total costs $C$ connected to fraction $X$, if $X$ is a useful fraction.

The manual associated with the NORDIC tool is applicable to the schemes in industries. Therefore, practical application of the NORDIC model is useful for businesses in general. It may also be possible to apply the model to developing countries, subject to training.

Notably, the NORDIC model and its related manual promotes the circular economy, a regenerative system in which resource input and waste, emission, and energy leakage are minimized by slowing, closing, and narrowing energy and material loops [25]. The launched tool namely reduces spillages at the source, by providing economic incentives to achieve that goal. 


\section{Conclusions}

\subsection{General Conclusions}

The main hypothesis in this paper is that the flows of physical and intangible utilities through entities of different kinds can be improved by applying the NORDIC model. The hypothesis is verified, because the logics of the theory designed support this conclusion, and because the introduced theorems are mathematically correct. The results from the case study support the main goal of facilitating the daily use of the NORDIC model by civil servants and operators. As more communities adopt the NORDIC model, the objectives of improving the economic, technological and environmental conditions in the organisations will be supported. The gap is filled in the existing research, regarding novel, economic instruments to manage communities and other organisations needing artifacts like the versatile NORDIC model, which was developed with the very aim to improve communities.

The results of the study, and the previous discussion, provide answers to the research questions posed, regarding how to use the NORDIC model to improve the efficiency of economic units, such as nations and communities, and how an economic instrument can be designed and modified for this purpose. The provided research contribution involves the development of a versatile, economic tool that enables managers to better understand how their organisations can become more efficient in economic, environmental and technical terms. In this study, this tool has been shown to be useful for public finances, particularly the health care, education and social services, and to help them improve the well-being of communities and municipalities.

The work contributes to the literature by providing novel solutions to promote the optimization of the economic efficiency and to assist public managers, and managers in industries, to improve their companies' performance. This improved management situation in the public and the private sector is the major value of knowledge added by this paper.

The real finding of the present study is that the NORDIC model represents a versatile theory to improve the situation in various entities, such as nations. The evidence for this statement consists of the realistic results of the performed case study with real-world data.

The novelty of the approach is the innovative usage of the shadow cost construct to create the economic incentives for improvement of the functionality of management systems. The introduction of a single key indicator to simultaneously monitor most aspects of interest for a management system is a highlight. The most interesting findings are the method to facilitate managers' policy decisions and their positive impact on the economic development that is a prerequisite for a sound technology that promotes environmental sustainability.

The method aids managers and practical operators to reduce losses in economic systems and improve the efficiency, based on the well-known concept of 
shadow costs. The most important conclusions, based on my developed model and the case study, are as follows.

1) The research is useful for managers to reduce losses in their organisations.

2) Managers obtain an economic instrument to monitor, manage and evaluate.

3) The constructed economic incentives improve the utilization of resources.

4) Cost-effectiveness and equity increase due to the reduced risk of spillages.

5) Managers can apply economic instruments to prevent people's discontent.

The main limitation of the introduced methodology is its less specified impact on the targeted communities. The employed shadow costs namely work on a general level, which mainly gives overall results for the current entities of interest. Therefore, some additional algorithms should be developed, and integrated into the present NORDIC model, to enable a more specific impact on the sub-units that are intended to be improved by the model.

In the future, studies could be conducted to determine how the NORDIC model can be applied to larger units. There is potential to apply the model to the international context, particularly as regards higher policy analysis organizational levels within major areas of social concern, for example, the migration issue and how to improve the workforce.

\subsection{Benefits of Using the Model}

- The NORDIC model gives managers a versatile management tool.

- The model is applicable to the public sector and commercial activities.

- The method provides a key indicator to assess and improve performance.

- The method is based on the well-known concept of shadow costs.

- The method is comprehensible, robust and easy to grasp.

\subsection{Recommendations}

- Apply the NORDIC model to organisations to improve their performance.

- Apply the NORDIC model based on the manual presented in this study.

\section{Conflicts of Interest}

The author declares no conflicts of interest.

\section{Availability of Data and Material}

All data generated or analysed during this study are included in this article.

\section{Research Involving Human Participants and/or Animals}

No human participants or animals were directly involved in this study.

\section{The Author's Contribution to the Present Study}

J. Stenis-Development of the introduced concept; review of the literature; NORDIC model development, manuscript writing. 


\section{References}

[1] Stenis, J. (2005) Construction Waste Management Based on Industrial Management Models: A Swedish Case Study. Waste Management \& Research, 23, 13-19. https://doi.org/10.1177/0734242X05050184

[2] Stenis, J. (2005) Environmental Optimization in Fractionating Industrial Wastes Using Contribution Margin Analysis as a Sustainable Development Tool. Environment, Development and Sustainability, 7, 363-376. https://doi.org/10.1007/s10668-004-2377-Z

[3] Stenis, J. and Hogland, W. (2011) Optimization of Mining by Application of the Equality Principle. Resources Policy, 36, 285-292. https://doi.org/10.1016/j.resourpol.2011.05.004

[4] Stenis, J. and Hogland, W. (2014) Economic Optimization of Landfill Mining. Journal of Solid Waste Technology and Management, 40, 389-398. https://doi.org/10.5276/JSWTM.2014.389

[5] Stenis, J. and Hogland, W. (2016) Cost-Effectiveness of Recycling and Recirculation of Natural and Energy Resources Based on the Equality Principle. Environment, Development and Sustainability, 18, 95-109. https://doi.org/10.1007/s10668-015-9627-0

[6] Stenis, J. and Hogland, W. (2018) Guidelines for Practical Application of the Europe Model to Improve Production Units' Resource Efficiency. The Open Waste Management Journal, 11, 41-49.

https://openwastemanagementjournal.com/VOLUME/11/PAGE/41/FULLTEXT

[7] Shadow Price (2021) In Wikipedia, the Free Encyclopaedia. https://en.wikipedia.org/wiki/Shadow_price

[8] Sekerka, L. and Stimel, D. (2012) Environmental Sustainability Decision-Making: Clearing a Path to Change. Journal of Public Affairs, 12, 195-205.

https://doi.org/10.1002/pa.1433

[9] Ooi, G.L. (2007) Urbanization in Southeast Asia: Assessing Policy Process and Progress toward Sustainability. Journal of Industrial Ecology, 11, 31-42. https://doi.org/10.1162/jie.2007.1246

[10] Blake, D. (2001) Contextual Effects on Environmental Attitudes and Behaviour. Environment \& Behaviour, 33, 708-725. https://doi.org/10.1177/00139160121973205

[11] Huang, J., Liu, Y., Ma, L. and Su, F. (2013) Methodology for the Assessment and Classification of Regional Vulnerability to Natural Hazards in China: The Application of a DEA Model. Natural Hazards, 65, 115-134. https://doi.org/10.1007/s11069-012-0348-5

[12] Hills, P. (2005) Environmental Reform, Ecological Modernization and the Policy Process in Hong Kong: An Exploratory Study of Stakeholder Perspectives. Journal of Environmental Planning and Management, 48, 209-240. https://doi.org/10.1080/0964056042000338154

[13] Phyllis, Y., Grigoroudis, E. and Kouikoglou, V. (2011) Sustainability Ranking and Improvement of Countries. Ecological Economics, 70, 542-553.

https://doi.org/10.1016/j.ecolecon.2010.09.037

[14] Gavazov, K.S., Peringer, A., Buttler, A., Gillet, F. and Spiegelberger, T. (2013) Dynamics of Forage Production in Pasture-Woodlands of the Swiss Jura Mountains under Projected Climate Change Scenarios. Ecology and Society, 18, 38-51. https://doi.org/10.5751/ES-04974-180138

[15] Jepson, E. (2004) Human Nature and Sustainable Development: A Strategic Chal- 
lenge for Planners. Journal of Planning Literature, 19, 3-15.

https://doi.org/10.1177/0885412204264529

[16] Dror, Y. (2017) Public Policy Making Re-Examined. Routledge, New York. https://doi.org/10.4324/9781315127774

[17] Vedung, E. (2011) Policy Instruments: Typologies and Theories. In: McCormick, J., Ed., Carrots, Sticks and Sermon, Transaction Publishers, Piscataway, Chapter 1.

https://www.taylorfrancis.com/chapters/edit/10.4324/9781315081748-2/policy-instr uments-typologies-theories-marie-louise-bemelmans-videc-ray-rist-evert-vedung-e vert-vedung

[18] Matsumura, T. and Tomaru, Y. (2015) Mixed Duopoly, Location Choice, and Shadow Cost of Public Funds. Southern Economic Journal, 82, 416-429.

https://doi.org/10.4284/0038-4038-2013.153

[19] Pentland, A. (2015) Simple Market Models Fail the Test. Nature, 525, 190-191. https://doi.org/10.1038/nature15215

[20] Statistics Sweden (2021) Annual Accounts for Municipalities and Regions. https://scb.se/en/finding-statistics/statistics-by-subject-area/public-finances/local-g overnment-finances/annual-accounts-for-municipalities-and-regions

[21] Ekonomifakta (2021) The Swedish State's Expenses 2018. https://www.ekonomifakta.se/Fakta/Offentlig-ekonomi/Statsbudget/Statsbudgetens -utgifter/?graph=/25203/10,16/all

[22] Trading Economics (2021) Sweden GDP from Public Administration. https://tradingeconomics.com/sweden/gdp-from-public-administration

[23] List of Countries by Life Expectancy (2021) In Wikipedia, the Free Encyclopaedia. https://en.wikipedia.org/wiki/List_of_countries_by_life_expectancy

[24] Trading Economics (2021) Sweden GDP. https://tradingeconomics.com/sweden/gdp

[25] Circular Economy (2021) In Wikipedia, the Free Encyclopaedia. https://en.wikipedia.org/wiki/Circular_economy 